\title{
ДЕЯТЕЛЬНОСТЬ ПРОФСОЮЗОВ ПО ЛИКВИДАЦИИ НЕГРАМОТНОСТИ В 1920-Е - 30-Е ГГ.: ПРОБЛЕМЫ И РЕШЕНИЯ
}

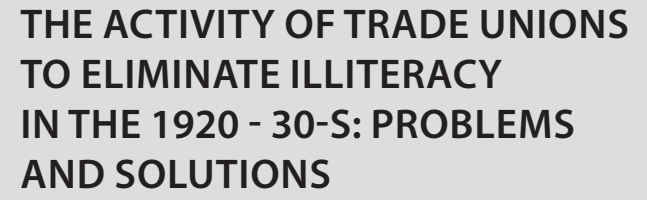

THE ACTIVITY OF TRADE UNIONS TO ELIMINATE ILLITERACY

IN THE 1920 - 30-S: PROBLEMS AND SOLUTIONS

A. Veterkov

Summary: The article is devoted to the activities of the Soviet trade unions to eliminate illiteracy in the 20 s - 30s. last century. The main focus is on the study of the qualitative characteristics of the process. The main problems faced by the trade union organizations are identified, the ways of solving the difficulties that have arisen are analyzed.

The aim of the study is to reveal the difficulties faced by trade union organizations in the process of combating illiteracy and measures taken to overcome them.

The material of the research was unpublished archival documents and scientific research on the topic.

Keywords: illiteracy, educational program, education, trade unions, AllUnion Central Council of Trade Unions.

\author{
Ветерков Александр Иванович \\ К.и.н., дочент, Российский университет \\ транспорта (РУТМИИТ), г. Москва \\ aveterkov@yandex.ru
}

Аннотация: Статья посвящена деятельности советских профсоюзов по ликвидации неграмотности в 20-е - 30-е гг. прошлого столетия. Основной упор сделан на исследовании качественных характеристик процесса. Выявлены основные проблемы, с которыми столкнулись профсоюзные организации, проанализированы пути решения возникших трудностей.

Целью исследования является раскрытие трудностей, с которыми столкнулись профсоюзные организации в процессе борьбы с неграмотностью и предпринимаемые меры для их преодоления.

Материалом исследования послужили неопубликованные архивные документы и научные исследования по теме.

Ключевые слова: неграмотность, ликбез, образование, профсоюзы, ВЦСПС.
$\mathrm{P}$ еволюционные события в нашей стране, начавшиеся после 1917 г. поставили много задач, которые необходимо было решать новому руководству страны. Начались существенные преобразования во многих сферах общественной жизни, которые затронули и духовную сферу. Происходит огромная трансформация всех устоев - преобразованию подвергаются система государственного управления, право, экономика, начинаются процессы, требующие изменения ментальности и сознания жизни обычных людей. Одной из главных задач советского правительства становится повсеместная ликвидация неграмотности (применительно к исследуемой эпохе - «ликвидация безграмотности»). Массовое обучение неграмотного взрослого населения в Советской России и СССР приобретает широкомасштабный характер. Цифры количества неграмотного и малограмотного населения крайне противоречивы. В различных социальных группах процентные показатели неграмотного населения существенно разнились - так, наиболее проблемными группами являлись представители национальных меньшинств и женщины. Уровень грамотности был неоднородным и географически - наибольшее количество грамотного населения проживало в крупных городах и в западной части страны.

Исследователи до сих пор не могут дать точного ответа на вопрос о количестве неграмотного населения страны в первой четверти XX в. Это объясняется отсутствием чётко принятых критериев грамотности применительно к исследуемой эпохе. Согласно различным историческим источникам и историографическим материалам, процент неграмотного населения к 1917 г. составлял от $27 \%$ до $56 \%$ от всего населения Российской империи. По исследованиям А.И. Уткина и Н. Ерофеева, уровень грамотности населения в Российской империи к 1914 г. составлял 27-30\% [16,с.20]; [10]. По мнению В.А. Мельянцева, ряд зарубежных исследователей отмечают, что уровень грамотного населения в России на данный период времени составлял 35-38\% [13]. Г.В. Вернадский даёт следующую оценку - количество грамотного населения составляло 45\% [2,с.245], и т.д.

Как видим, разброс оценок исследователей относительно количественного состава неграмотного населения к 1917 г. достаточно велик. Следует отметить, что подобная ситуация отмечается и по отношению к более позднему периоду в истории нашей страны - к «культурной революции» 1920-х - 30-х гг. в СССР. Непосредственными причинами столь явного расхождения во взглядах является следующее. Во-первых, сложность методики определения неграмотного населения, т.е. отсутствие чётких критериев отнесения к неграмотным того или иного человека. Причём следует отметить, что методика так и не была в полной мере разработана и к 
1930-м гг. Данное положение подтверждается выдержкой из доклада Московского бюро по вопросу подготовки к 1934/35 учебному году школ взрослых. Основным недостатком прошлых лет работы в ликбезе указывалось «отсутствие точности в учёте подлежащих обучению» [9,л.48]. В целом ряде регионов (в основном на национальных окраинах) вообще отсутствовала практика переписи неграмотного и малограмотного населения $[9, \pi .95]$.

Также среди современных исследователей отсутствует единая точка зрения на то, что следует понимать под ликвидацией неграмотности. Долгое время в советской историографии господствовало мнение, согласно которому под ликвидацией неграмотности следует понимать массовое обучение взрослого населения чтению и письму. В данном контексте следует выделить исследования А.М. Ивановой[11], Д.Ю. Элькиной[19], Куманёва В.С.[12] и др.

Сторонники данной точки зрения обращаются к Декрету Совета Народных Комиссаров «О ликвидации безграмотности среди населения РСФСР» от 26 декабря 1919 г. Уже 9 ноября 1917 г., выступая на заседании Государственной комиссии по просвещению народный комиссар А.В. Луначарский высказал следующее: «всякая истинно демократическая власть в области просвещения в стране, где царит неграмотность и невежество, должна поставить своей целью борьбу против этого мрака» [15,с.299]. Согласно декрету, предусматривалась полная ликвидация неграмотности во всей советской России. Это означало, что всё население РСФСР, «в возрасте от 8 до 50 лет, не умеющее читать и писать, обязано обучаться грамоте на родном или русском языке по желанию» [5,л.38]. Чёткие сроки данного процесса определены не были - в зависимости от условий каждого региона органы советской власти на местах должны были самостоятельно решать, за какой промежуток времени поставленная задача будет выполнена. Советские исследователи трактовали ликвидацию неграмотности, опираясь на данный декрет.

Однако существует и иная точка зрения на данную проблему. Главным образом, её сторонники являются представителями зарубежной исторической науки. Здесь следует выделить несколько тенденций. Согласно первой, советская власть лишь развила те процессы, которые уже с успехом происходили в дореволюционной России [22], [23]. По мнению других учёных, это был величайший исторический эксперимент, завершившийся не просто ликвидацией неграмотности среди взрослого населения страны, но и созданием человека нового типа, формированием абсолютно новой идейной гегемонии в обществе [20], [21].

Необходимо отметить, что ряд современных иссле- дователей полагает, что ликвидация неграмотности не была завершена в довоенную эпоху, и трудности, с которыми сталкивалось советское правительство в 20-30-е гг. минувшего столетия, перекинулись и на послевоенный период развития нашей страны [17].

Исходя из вышеизложенного, целью нашего исследования является не акцентирование внимания на количественных показателях процесса, которые точно установить не представляется возможным, а раскрытие его качественной составляющей. Целью ликвидации неграмотности являлось не только просвещение масс, но и «перековка» мировоззрения людей. Ликвидация неграмотности была одной из составных компонентов культурной революции, способствующей не только обучению населения грамоте, но и утверждению марксистско-ленинской идеологии в качестве господствующей. В рамках кампании по ликвидации неграмотности должна была появиться интеллигенция нового типа - социалистическая интеллигенция, пришедшая на смену дореволюционным работникам умственного труда, которая должна была осуществлять воспитательную функцию применительно к рабоче- крестьянским массам, как верным строителям общества нового типа.

Можно выделить два этапа развития кампании по ликвидации неграмотности. Первый этап охватывает период с 1919 г. до конца 1920-х гг.; второй этап следует датировать довоенным периодом истории нашей страны, который пришёлся на 1930-е - начало 1940-х гг.

На первом этапе значительной была роль профсоюзных и других общественных организаций. Основополагающей задачей являлось обучение основам письма, чтения и счёта; политико-пропагандистская составляющая не оказывалась такой приоритетной, как в последующий период.

На втором этапе, начиная с 1930-х гг., происходит изменение вектора государственной политики в сторону складывания тоталитарного режима. В пунктах ликбеза усиливается роль политической составляющей, возникает идея по превращению школ ликвидации неграмотности в школы политграмоты. В программы преподавания стали включаться политчасы, руководство которыми возлагалось на партийные и комсомольские кадры. Профессиональные союзы к 1930-м гг. теряют свою автономию, встраиваясь в часть государственного аппарата. Образовательно-просветительная функция постепенно перестаёт быть господствующей, заменяясь политико - идеологической.

Мероприятия по ликвидации неграмотности оказались настолько масштабными, что опираясь только на государство и его органы, данный вопрос было не решить. Специальным декретом от 19 июля 1920 г. была 
создана Всероссийская чрезвычайная комиссия по ликвидации безграмотности (ВЧК л/б). Непосредственное руководство комиссией осуществлял Наркомпрос (государственный орган). На региональном уровне создавались губернские и уездные комиссии, которые координировали деятельность по ликвидации неграмотности на подведомственных им территориях. Необходима была поддержка - и в процесс ликвидации неграмотности включаются многочисленные общественные организации, в том числе и профсоюзы. Массовую работу проводили ячейки РКП(б), (позднее - ВКП(б)), комсомольские, кооперативные организации, общество «Долой неграмотность». Из всех вышеперечисленных, именно профсоюзы являлись наиболее массовыми общественными организациями, соответственно охват взрослых граждан, подлежащих обучению грамоте, у них был шире.

Ещё до принятия Декрета от 26 декабря 1919 г. профсоюзные организации предпринимают первые шаги по искоренению неграмотности в стране. В 1919 г. культурно-просветительным отделом ВЦСПС была разработана специальная инструкция, в которой фабрично-заводским комитетам и профессиональным союзам рекомендовалось организовать школы грамоты с трёхмесячным сроком обучения. Профсоюзные организации были более близки к трудящимся гражданам страны. Применялся творческий новаторский подход - профсоюзы включаются в решение проблемы ещё до того, как она практически начинает решаться на государственном уровне.

Профсоюзы начинают усиленно включаться в процесс по борьбе с неграмотностью. Различные исследования не дают основания установить точное количество школ ликбеза, организованных профсоюзами для взрослых. Сами исследователи отмечают, что данные, которыми они обладают, «весьма неточные»[3,с.6]. Это было вызвано целым рядом причин. Во-первых, не все союзы давали информацию в ВЦСПС; во-вторых, передаваемые данные отличались противоречивостью и неточностью - в ряде губерний и областей в 1920-х - 30-х гг. «не проводили переписи неграмотного и малограмотного населения, исключая промышленные и городские пункты»[9,л.95]; в-третьих, некоторые школы существовали формально, для отчётности, и многочисленные проверки показывали, что работа в них не велась [9,л.96].

В процессе ликвидации неграмотности профсоюзы столкнулись с целым рядом трудностей. Одна из главных - ограниченность материальных ресурсов, а в ряде регионов полное их отсутствие. Это стало одной из главных причин того, что была признана необходимость об обязательности обучения людей в возрасте от 18 до 30 лет, граждане остальных возрастов должны были привлекаться в качестве добровольцев. Профсоюзы ока- зались единственной организацией, которая могла сплотить людей по профессиональному признаку и организовать необходимую работу в этом вопросе. Практика внедрения коллективных договоров приводит к тому, что значительную часть собственных средств профсоюзы начинают тратить на образовательные учреждения.

Наибольшие трудности проявлялись на периферии. Если во многих ликпунктах, находящихся в ведении союза Всеработземлес (с 1926 г. - профсоюз сельскохозяйственных и лесных рабочих), ситуация была более критичной - «ученики изучали алфавит при свете лучин, вместо бумаги использовали дощечки, вместо карандашей уголь»[1,с.14], то в городских ликпунктах, находящихся в ведении профсоюзов, подобных сложностей отмечено не было.

В докладных записках по ликбезам, относящимся к ведению профсоюзов, отмечается нехватка помещений, когда занятия школ ликбеза проходили часто в красных уголках при рабочих бараках, либо даже в коридорах. Нередко возможность открытия школ была, но по разного рода причинам препятствия чинились ответственными работниками. Так, например, перед началом 1927/28 учебного года в г. Ростове Ярославской губернии на просьбу рабочих предоставить помещение для школы на фабрике «Рольма» председатель фабзавкома заявил им следующее: «бросьте ребята дурить, вы здесь намусорите»[18,л.249]; в г. Ленинграде отмечалось, что «хорошие методические кабинеты, приспособленные физические и химические кабинеты часто на заводских школах не имеются»[9,л.14]; повсеместно вплоть до конца 1930-х гг. фиксировалось отсутствие необходимой учебной литературы и тетрадей - «из-за учебников и тетрадей срывается учёба, большинство школ обеспечены учебниками и сейчас на 50\%» (Уральский областной комитет союза Промкомжилстроя) [9,л.67об.]; проблемным было наличие литературы на языках национальных меньшинств. Профсоюзные и советские органы повсеместно пересматривали жилой фонд и значительную часть резерва отдавали под школы и пункты ликбеза, расширялось строительство оборудованных для учебных занятий зданий.

Интересной иллюстрацией является выдержка из докладной записки культотделу ВЦСПС «О подготовке к новому учебному году школ взрослых и состоянии ликбезработы Чечено-Ингушской области» за 1933 г. (информация, приведённая в этой записке помогает оценить состояние дел также применительно к 1920-м гг.): «область не имеет национальных учебников. Прошлогодние учебники непригодны. По вине КОГИЗа (Книготоргового Объединения Государственных Изданий - прим. авт.) в букварях была пропущена буква "Ж". Ими пользовались в течении года и до последнего времени никто не обнаружил этой ошибки... Русскими 
учебниками область обеспечена полностью, однако из ряда районов сообщали, что все учебники расхищаются и раскуриваются» $[9, л .95]$.

Ещё одной проблемой являлась нехватка педагогических кадров. Особо остро данная ситуация проявлялась в сельской местности. Постреволюционные события и последовавшая после них гражданская война сильно ударили по учительству. Учителя часто оставались без оплаты своего труда; известны случаи, когда «деревенские жители часто сами собирали им еду, приобретали новую одежду и обувь»[16,с.14]. Недоукомплектованность преподавательского состава отмечалась на протяжении всего периода НЭПа; остро это проблема стояла и в годы первых пятилеток. На это указывают данные по руднику им. Рыкова (Донбасс), относящиеся к 1932/33 учебному году: «особенно остро в прошлом учебном году стоял вопрос с кадрами педагогов. Большинство ликбез работников мало квалифицированы, а иногда их совсем не оказывалось» $[9, л .116]$.

Решение проблемы осуществлялось с помощью членов профсоюза Рабпрос (работников просвещения). Активизировались процессы обучения педагогических кадров. Для ускорения и распространения процесса по ликвидации неграмотности объявлялись специальные кампании - культпоходы. Самым значимым событием являлся культпоход 1928 г. - Всесоюзный культурный поход за ликвидацию неграмотности. В условиях нехватки педагогических кадров была объявлена задача полной ликвидации неграмотности. К участию в культпоходе привлекалось всё грамотное население страны, но костяк составляли члены союза Рабпрос.

Сложности в процессе борьбы с неграмотностью наблюдались в ходе работы с отдельными социальными группами. Выделим несколько основных проблемных групп. Во-первых, это женщины. Вести данную работу было сложно, главным образом потому, что женщины были более привязаны к дому, семье, в меньшей степени вовлечены в общественную жизнь. Это понимало руководство ВЦСПС, и именно профсоюзы сыграли большую роль в ликвидации неграмотности среди женщин, оказав активную поддержку в этом вопросе обществу «Долой неграмотность». К 8 марта 1923 г. профсоюзы осуществили учёт всех неграмотных женщин - членов профсоюзов. Об этом говорят отчёты губернских и областных советов профсоюзов. Однако не будем забывать, что отчёты далеко не всегда соответствовали (и соответствуют) действительности, и цифры по ликвидации неграмотности разнятся из года в год.

Количественные показатели как по выявлению неграмотных, так и по ликвидации неграмотности установить достаточно сложно, как и по многим другим процессам, проходившим в 1920-х - 30-х гг. Ликвидации неграмотности была свойственна кампанейщина. В кратчайшие сроки победить неграмотность среди женщин (как и среди других категорий населения) не удалось. Так, согласно объяснительной записке к оперативному плану по ликвидации неграмотности, датированной 1928 г. «профсоюзы должны обратить внимание на то, что ликвидация неграмотности в значительной степени относится к женщинам, что среди неграмотных подавляющее большинство составляют женщины, что ликвидация неграмотности женщин - работниц особенно трудна потому, что женщины - работницы обычно несут на себе двойные тяготы: работу на фабрике и работу дома с детьми по хозяйству»[8,л.41]. В 1926 г. в брошюре ВЦСПС «Профсоюзы и ОДН» была отмечена «громадная задача по ликвидации неграмотности среди жён рабочих и членов их семей, осложнённая бытовыми условиями жён рабочих»[6,л.7]. Особенно тяжёлым было положение на национальных окраинах (данные по Средней Азии): «на Востоке... ввиду слабой сети организованных ликпунктов и кружков процент женщин попадающих туда по отношению к мужчинам ничтожен (не доходит 15\% в селе и $25 \%$ в городах)»[6,л.26].

Наиболее организованно и эффективно работа проводилась в губерниях и областях центральной России. Для борьбы с неграмотностью на предприятиях создавались благоприятные условия для работниц. Огромную роль по вовлечению женщин в школы грамоты сыграли женотделы. На селе женщины в массе своей продолжали оставаться неграмотными. Жительницы села отмечали, что им сложно посещать ликпункты из-за сильной загруженности по ведению хозяйства и воспитанию детей. Женотделы совместно с профсоюзом Всеработземлес организуют обучение крестьянок группами и по одиночке на дому. Женщины - члены профсоюза вели постоянную агитацию среди крестьянок о необходимости обучения. Осуществлялось это главным образом на сельских сходах. Союзом Всеработземлес активно привлекались работники союза Рабпрос, ведь учительство было основной культурно-просветительной силой на селе.

Ещё одной достаточно сложной категорией населения были батраки и сезонные рабочие, поэтому в профессиональных союзах, где у них было высокое процентное соотношение, работа велась с значительным замедлением. Объединение данных социальных групп в одну категорию объясняется тем, что основную массу сезонных рабочих составляли выходцы из сельской местности, которые нанимались либо к более зажиточным односельчанам (батраки), либо выезжали в другие местности, главным образом в города. Особенно тяжёлое положение складывалось в профсоюзе сельскохозяйственных и лесных рабочих (Всеработземлес). Причинами этого стал рост союза за счёт батраков в 1920-е гг., а возможности профсоюза были крайне ограничены вследствие слабости финансирования культфондов, низкой 
оплаты труда батрачества и сезонной безработицы. Из докладных записок культотдела союза Всеработземлес следует, что сельское население недостаточно активно стремится к обучению грамоте. Крестьяне считали, что данный вид деятельности отвлекает их от насущных жизненно важных дел. Следует отметить, это касалось не только крестьянства, но и городских трудящихся. Согласно выписке из протокола заседания культкомиссии Иваново-Вознесенского губпрофсовета от 1 декабря 1926 г. «рабочий вопрос ставит прямо: не запутывайте мою голову конспектами, а научите меня мало-мальски читать и писать... Рабочие говорят, мы учиться не против, но жалуются на семейное положение, на болезни» $[6, \pi .58]$.

Культотделы ВЦСПС отмечали, что по большинству союзов главным контингентом неграмотных были сезонные рабочие, и работа по ликвидации неграмотности вынуждена вестись на предприятиях преимущественно в период производственной деятельности. После сезонного закрытия производства закрывались и школы ликбеза. По возвращении на производство у рабочих отмечался рецидив неграмотности. Проблемой сезонных рабочих являлось то, что значительная их часть не могла обучаться вдали от предприятий, т.к. многие проживали на значительном удалении от них. Таким образом, «кратковременность производства, отдалённость мест жительства..., беспрерывная сменная работа, все эти условия, которые чрезвычайно осложняют работу по ликвидации неграмотности среди сезонных»[7,л.30об.].

Для закрепления полученных в ликбезах знаний и во избежание рецидива неграмотности профсоюзы активизируют работу по открытию клубов и изб - читален, посещая которые сезонные рабочие минимизировали риски, связанные с потерей полученных знаний.

Ещё одной категорией населения, где отмечены серьёзные трудности профсоюзной работы по ликвидации неграмотности были национальные меньшинства (нацмены). В объяснительной записке к оперативному плану по ликвидации неграмотности на 1926/27 учебный год отмечалась необходимость усиления темпа обслуживания народностей нерусского языка на 200\%. Это было связано с тем, что согласно данным 1924/25 учебного года констатировалось только 7,7\% обучающихся в ликпунктах меньшинств к общему количеству обучающихся в ликпунктах, что признавалось явно недостаточным и свидетельствовало о крайней слабости темпов и внимания к этой отрасли работы [7,л.95об.].

Борьба с неграмотностью на национальных окраинах потребовала подготовки кадров педагогических работников, преподававших на родном языке. Профсоюзные организации объявляли массовые культпоходы, вели активную агитацию среди населения национальных окраин. Работники культотделов профсоюзов способствовали не только обучению, но и просвещению работников. В регионах, населённых местным населением, методика профсоюзной работы ничем не отличалась от русскоязычных районов страны, за исключением необходимости общения и дальнейшего обучения на родном языке нацменов. У многих народов отсутствовала национальная письменность, что обостряло проблему.

Результаты борьбы за грамотность оставляли желать лучшего. В 1928 г. было созвано Всесоюзное совещание по вопросам агитации, пропаганды и культурного строительства. На нём отмечалось, что работа по ликвидации неграмотности находится в крайне тяжёлом состоянии. Это было связано со стремлением достичь высоких количественных показателей нередко в ущерб качественным. Отсутствовала чётко разработанная методика по ликвидации неграмотности среди взрослого населения, ощущалась острая нехватка преподавателей, учебников и методической литературы, препятствовала всеобщей грамотности и рассредоточенность населения.

В 1920-е гг., несмотря на все приложенные усилия как со стороны государства, профсоюзов и других общественных организаций, победить неграмотность не удалось. Связано это было с целым рядом факторов. Не хватало материально - технической базы для охвата обучением всего взрослого неграмотного населения страны; постоянно шёл рост потока неграмотных, обусловленный ростом числа членов профсоюзов и расширением СССР за счёт присоединения среднеазиатского региона (Туркестана); серьёзные трудности возникали из-за недофинансирования; не хватало профессиональных педагогических кадров - лишь в 1930-х годах в СССР появилось массовое педагогическое образование; невозможность часто применять полученные знания на практике приводили к рецидиву неграмотности.

Существенное позитивное влияние на победу над неграмотностью оказало введение всеобщего начального образования в 1930 г. Ликвидация неграмотности послужила ступенью для дальнейшего образования рабочих, в массе своей объединённых в профсоюзы. Получив азы грамотности, многие рабочие продолжили обучение в школах взрослых повышенного типа, где получали знания в рамках средней школы. Немало рабочих в дальнейшем поступало на рабфаки, в ССУЗы и ВУЗы. Несмотря на вышеперечисленные трудности, профсоюзы способствовали тому, что из неграмотных в массе своей трудящихся выросли деятели науки, культуры, образования, появились новые административно-управленческие кадры. 


\section{ЛИТЕРАТУРА}

1. Белоусова 0.А. Борьба с безграмотностью в первые годы становления советской власти // Теория и практика социогуманитарных наук. 2019. №2. С.13-19.

2. Вернадский Г.В. Русская история. М.: Аграф, 1997.542 с.

3. Ветерков А.И. Профсоюзные организации и борьба с неграмотностью в 1920-е годы (на примере Ярославской губернии) // Современная наука: актуальные проблемы теории и практики. Серия «Гуманитарные науки». 2020. №5-2. С.5-9.

4. Галин С.А. Исторический опыт культурного строительства в первые годы Советской власти (1917-1925). М.: Высшая школа, 1990. 144 с.

5. Государственный архив Российской Федерации (ГАРФ). Ф. Р-130. Оп.2. Д.1.

6. Государственный архив Российской Федерации (ГАРФ). Ф. Р-5451. Оп.10. Д.475.

7. Государственный архив Российской Федерации (ГАРФ). Ф. Р-5451. Оп.10. Д.476.

8. Государственный архив Российской Федерации (ГАРФ). Ф. Р-5451. Оп.12. Д.619.

9. Государственный архив Российской Федерации (ГАРФ). Ф. Р-5451.0п.18.Д.538.

10. Ерофеев Н. Уровень жизни населения в конце XIX - начале XX в. // Скепсис: научно-просветительский журнал. [Электронный pecypc]: https://scepsis.net/ library/id_2163.html. Дата обращения: 28.09.2021.

11. Иванова А.М. Что сделала Советская власть по ликвидации неграмотности среди взрослых. М.:Учпедгиз, 1949. 96 с.

12. Куманёв В.С. Социализм и всенародная грамотность. Ликвидация массовой неграмотности в СССР. М.: Наука, 1967. 328 с.

13. Мельянцев В.А. Россия за три века: экономический рост в контексте мирового развития // 0бщественные науки и современность.2003.№5.С.84-95. [Электронный ресурс]: https://web.archive.org/web/20081009064502/ http://www.iaas.msu.ru/pub_on/vamel/russ.htm. Дата 06ращения: 29.09.2021.

14. Полякова Н.В. Укрепление идейно-политического единства советских профсоюзов в борьбе за социализм. М.: Профиздат, 1980. 200 с.

15. Рид Дж. Десять дней, которые потрясли мир. М.: Госполитиздат, 1957. 352 с.

16. Уткин А.И. Первая мировая война. М.: Алгоритм, 2001.592 с.

17. Фишева А.А. Общее образование взрослых на территории РСФСР в 1930-е - 50-е гг. Дисс. канд. ист. наук. СПб.: СПбГУ, 2015. 325 с.

18. Центр документации новейшей истории Государственного архива Ярославской области (ЦДНИ ГАЯО). Ф.1087. Оп.1. Д.1409.

19. Элькина Д.Ю. На культурном фронте. Из истории борьбы за ликвидацию неграмотности в СССР. М.: Издательство АПН РСФСР, 1959. 144 с.

20. Fitzpatrick S. Education and Social Mobility in the Soviet Union, 1921-1934. Cambridge:Cambridge University Press, 1979. 355 p.

21. Fitzpatrick S. The Cultural Front. Power and Culture in Revolutionary Russia. Ithaca: Cornell, University Press, 1992. $296 \mathrm{p}$.

22. Pennar J., Bakalo I., Bereday G.Modernization and diversity in Soviet Education. New York, 1971. P. 8-15.

23. Tomasic D. The Impact of Russian Cultureon Soviet Communism. Glencoe, 1953.

(с) Ветерков Александр Иванович (aveterkov@yandex.ru) 